\title{
THEORETICAL AND CONCEPTUAL PRINCIPLES OF THE SYSTEM OF PUBLIC MANAGEMENT OF TRANSPORT INFRASTRUCTURE DEVELOPMENT IN A "SMART CITY"
}

\section{Zemliak A. O.}

\section{INTRODUCTION}

Current trends in the development of modern Ukrainian cities are still quite difficult to fit into the framework of the European scenario of intellectualized urban development. A number of systemic problems, including, in particular, political and economic instability, aggravation of geopolitical risks, significantly constrain the progressive movement of large cities of Ukraine on the way to improving utilities, deepening their integration to increase the comfort of living. In this light, the priority issue of urban development that needs to be addressed is the definition of key concepts that explain the meaning and reveal the essence of the "smart city" as an object of public administration, a managed system of providing its citizens with improved services. Many authors explore this issue in the context of municipal development management. However, in practice, the issue of becoming a smart Ukrainian remains only a farreaching prospect, which determines the relevance of further research in this direction and the preliminary intensification of scientific research in the direction of defining definitions.

\section{Conceptual principles of the system of public management of transport infrastructure development}

National interests in the economic sphere reflect the needs of the Ukrainian people in appropriate living conditions, achieving a quality of life and socio-cultural development, the balance of economic interests of the individual, society and the state. Their priority is determined taking into account the resource, scientific and production potentials of the country, the development of its economy, as well as the foreign economic situation and certain strategic guidelines for socio-economic progress of Ukraine.

National economic interests are one of the central guidelines for the development of economies in all countries. Adoption of legislative acts, implementation of socio-economic reforms, support of certain sectors of 
the national economy, decision-making on accession to international economic organizations, integration within integration entities - all this must be done in accordance with national economic interests ${ }^{1}$.

Economics has accumulated considerable experience in analyzing the nature of interests in general and national economic interests in particular and their place in public policy.

Modern transport infrastructure contributes to the organization of economic space, ensures the further implementation of the spatial division of labor and development of new territories, thus expanding the limits of exploitation of natural resources and providing an important impetus for the influx of people into these areas.

In the case of insufficient intersectoral, interregional coordination of transport infrastructure development, there is an irrational use of resources, increased costs, which leads to a decrease in efficiency and competitiveness of the entire national economy. This presupposes the importance of the state pursuing a sound economic policy aimed at ensuring the balanced development of transport infrastructure. The development of such a policy should be carried out taking into account the systemic properties of transport infrastructure as a component of the production infrastructure of the country's economy, which provides the socio-economic development needs of its regions.

In the early 1990s in Ukraine, transport infrastructure was understood as a set of areas of activity that serve the market, necessary for the transition of the economy to developed market relations. However, in defining new economic laws, concepts and categories in the modern domestic economic encyclopedic literature provides the following classification of infrastructure - innovative, international, including industrial, market and social, ie without a separate definition of transport infrastructure (it is attributed to the elements of industrial infrastructure as part of the international), which in our opinion is a certain omission and needs to be refined and clarified in the future.

Differences in the definitions of transport infrastructure in the economic literature indicate that a single methodological approach has not yet been developed. This is largely due to the nature of the goals and objectives, the composition of the transport infrastructure and the sectoral focus of the work.

\footnotetext{
${ }^{1}$ Kolupaieva I., Shevchenko O. (2019) Justification of scenarios of state regulatory policy of Ukraine. Proceedings of the International conference of Innovation in Science and Education. March 20-22. Prague Czech Republic.
} 
It should be noted that there are different views on the composition of transport infrastructure. Some authors refer to it only as transport organizations, which sharply narrows the concept of transport infrastructure and reduces it to the infrastructure of transport services. Other authors, on the other hand, suggest an overly broad interpretation of transport infrastructure, including all national institutions, as well as a system of government and administration that regulates the economy. In this case, it is rather a system of transport infrastructure management.

Implementation of the approach to state regulation of the system of public management of transport infrastructure development requires the formation of appropriate conceptual provisions that would outline the main goal, a holistic system of relevant priorities of state regulation and a set of tools to achieve them.

Before proceeding to the formation of such a concept, it is necessary to first consider the content and functionality of mechanisms for state regulation of innovative development of transport infrastructure, which will contribute to a fuller understanding of the logic and specifics of state regulation of transport infrastructure. It should be noted that the implementation of state regulation of innovative development of transport infrastructure in Ukraine is implemented using an intellectualpartnership approach, which has a number of features for transport infrastructure.

First, the modernization and accelerated development of the transport system are complex, which is expressed in the need for state regulation with the direct participation of the executive branch.

Secondly, a high degree of cooperation between the Ministry of Infrastructure and its subordinate bodies such as the State Aviation Service of Ukraine, the State Service of Ukraine for Transport Safety, the State Agency for Highways, the State Agency for Infrastructure Projects of Ukraine, the State Service of Ukraine for Maritime and River Transport is needed. and other executive bodies, as well as directly by the subjects of innovation.

At the same time, the implementation of the intellectual-partnership approach presupposes a long-term strategic nature of transformations, which is due to the need to change the quality of the transport system on the innovative path of its development. Thus, the significant scale of transport infrastructure, the duration of the main strategic measures, as well as the presence of a significant delay in time between the implementation of costs and results form objective reasons for creating a basis for government support in the form of direct capital investments 
from the consolidated budget and in the form of state regulation and support for the development of transport infrastructure at the international level.

The adoption of the National Transport Strategy of Ukraine until 2030 has identified priorities for the development of state transport policy, the main directions of development of the country's transport infrastructure, the tasks of institutional reforms, as well as the main tasks of the transport system. According to the strategic plan, one of the main principles of development of transport infrastructure of Ukraine in the context of globalization is innovation and focus on sustainable development, as well as the development of competition and market formation of transport services, where each user can choose the most acceptable mode of transport services. and quality. The lack of a unified approach to the separation of the list of mechanisms of state regulation of the development of transport infrastructure requires the aggregation of the most important of the existing mechanisms into a single effective system, the so-called methodological basis.

In addition to the mechanisms of external state regulation of the development of transport infrastructure V. Stepanov also proposes to take into account the mechanism of internal self-government of enterprises, which is based on the ability of enterprises subordinated to the Ministry of Infrastructure to respond in a timely manner.

O. Ignatiuk and A. Pavliuk use another approach to the classification of mechanisms of state regulation of transport infrastructure development in their research. Among the main mechanisms of state regulation of the transport system of Ukraine, which are entrusted to the government in the person of the Ministry of Infrastructure and its subordinate bodies, they distinguish:

1. Strategic planning.

2. Budgetary mechanism.

3. Legal mechanism.

4. The mechanism of tariff and price regulation.

5. Control and supervision mechanism.

6. Licensing.

New economic conditions and integration changes require the state to constantly review and improve the legal framework governing transport infrastructure. The need to approve annual programs, priority areas of activity, main socio-economic objectives, targeted funding programs, etc., determines the constant indicative influence of the state. According to $\mathrm{V}$. Volik, regulatory regulation of transport infrastructure is a system 
of rules established by the competent authorities (central executive bodies). The main purpose of regulatory regulation is to determine the legal status of the subjects of legal relations in the field of transport, to establish the procedure for carrying out transport activities; implementation of jurisdictional and security regulation.

In addition, it should be noted that many scholars distinguish between transport legislation in terms of vertical and horizontal levels of regulation. For example, E. Dovzhenko proposes to consider the legislation on transport at the sectoral level and differentiate all legal acts into general transport, the purpose of which is to establish general legal and organizational principles of the transport industry, and specific transport-sectoral legislation, which aims to draw up acts for regulation of public relations of certain transport categories.

Thus, the subjects of the normative-legal mechanism of transport infrastructure development are: the President of Ukraine, the Verkhovna Rada of Ukraine, the Cabinet of Ministers of Ukraine and the Ministry of Infrastructure of Ukraine, as well as local governments and local executive bodies.

Analyzing the institutional features of the development of transport infrastructure, according to N. Ulyanytska, it is necessary to take into account that the management of the development of any production system is a function that provides a purposeful impact on the production base. The only thing of interest is effective and optimal management, which consists of two stages. At the first stage the directions defining a necessary condition of object of management and characterized by a set of technical and economic indicators are developed. The calculation of indicators is based on a certain mathematical interpretation of the existing dependencies between them, which is a necessary condition for the formalization of the planning process and increase its scientific validity. In the second stage (regulation) there is a direct impact on the object of management in accordance with the characteristics of the current market mechanism. Regulation of transport development requires additional consideration of numerous factors, taking into account the solution of management problems.

Developing the above provision, it should be noted that the institutional mechanism for regulating the development of transport infrastructure contributes to the tasks of the strategic mechanism and forms a bridgehead for strategic planning in the context of developing effective programs and standards. 
Speaking about the strategic mechanism of regulation of transport infrastructure, it should be noted the list of the main state strategic documents, the implementation of which has an impact on the development of transport infrastructure, among them:

- Order of the President of Ukraine "On urgent measures to reform and strengthen the state";

- Information on the status of implementation of the Ministry of Infrastructure of the Decree of the President of Ukraine "On urgent measures to reform and strengthen the state";

- Resolution of the Verkhovna Rada "On the Program of Activities of the Cabinet of Ministers of Ukraine";

- Resolution of the Cabinet of Ministers of Ukraine "On approval of the Program activities of the Cabinet of Ministers of Ukraine ".

It should be noted that the implementation of organizational regulation of transport infrastructure does not require a clear legal framework. The functioning of this mechanism can be implemented through meetings, conferences and conferences. Implementation of material and technical operations is an organizational form of activity that does not require a clear legal form and has an auxiliary purpose in ensuring the management process in the field of urban transport.

The financial mechanism for regulating the development of transport infrastructure is used to modernize the existing transport and logistics infrastructure by investing in relevant promising and priority projects and programs. This means that they should aim for resource support for the implementation of developed programs and projects in the transport sector. Since one of the current trends in world economic development is the integration of countries into a single regional space, it is the financial mechanism that distinguishes regional integration from other forms of international cooperation between states. Identifying problems and areas of cooperation that meet the interests of states, the need to deepen integration, active joint cooperation of countries in the field of transport can be based only on the creation of appropriate mechanisms. Their formation is one of the most important factors in the development of regional integration processes.

In order to develop a model of mechanisms for public governance of inclusive development in Ukraine, it is necessary to address the general trends in public governance in the context of globalization, covering seven trends, including those related to changing approaches and principles for the transition from public to public management of the main components of the external vector of globalization changes, in 
particular: the formation of the information society; formation of an innovative society; building a society of sustainable development; building civil society.

The systemic environment of public governance mechanisms in the context of global transformations is transformed under the influence of three major groups of factors: objective action of global megatrends, UN recommendations on achieving the Sustainable Development Goals, agreements and procedures of integration groups and intergovernmental agreements. which is also determined by the influence of three groups of factors: the level of institutional development, the level of human development and demographic situation (including migration flows), the level of economic development and industrial potential (including the country's share in world GDP, conditions for starting and running a business).

Using the method of modeling, as indirect scientific knowledge and later in the practice of public administration as an option for developing and making public administration decisions, you can build a model of mechanisms for public management of inclusive development, based on a systematic approach as a system of transformational mechanisms of public administration: innovative, information, sustainable development and development of civil society in the direction of inclusive development, taking into account the trend of public administration in the context of globalization and the internal capacity for their use.

It is also important to note that the systems approach is the fundamental basis for the development of any model and determines the set of elements of the system in the set of relationships and connections between them and forms an integrity that allows us to consider the system as a whole.

Post-Soviet institutional changes are extremely complex and contradictory. We believe that the "institutional inadequacy" of the state determines the appropriate institutional environment for the functioning and development of the economic system is not suitable for effective modernization of the national economy and the definition of the mechanism of public management of the country's development.

Thus, in the model of mechanisms of public administration of inclusive development of the country the tendency of development of public administration in the conditions of globalization changes provides: transition from classical conservative model to creative, such that operatively and innovatively reacts to changes in the world and in society; the need to account for the diversity of public administration; 
increasing the organizational capacity of public administration, ie the ability to provide the best management in the current conditions in society; ensuring balanced public administration (public administration and local self-government) and establishing effective relations with the population; increasing and, in part, changing the role of civil service and service in local governments as information and communication elements between public authorities and society; changing approaches to public administration, which are common ways to solve problems of state and planetary levels; change in the system of principles (change of priorities, expansion or reduction of staff), based on which public administration is implemented in the modern world.

It should be emphasized that the general trends in public administration in the context of globalization will determine the reaction of the government to these changes, and in Ukraine the reaction is delayed, which leads to lag and distortion of development in the context of globalization.

Avoiding these shortcomings in public administration systems is possible by introducing a system of transformational mechanisms that focus on adapting globalization processes within the country. Therefore, we have formed a system of mechanisms for public management of inclusive development of the country in the context of global transformations as a component of mechanisms: innovation, information, sustainable development and development of civil society.

Modernization has become one of the main trends in the modern development of economic systems, but has not created a positive potential for renewal and overcoming the crisis of the national economic system. Some researchers consider it necessary to focus not on modernization but on reconstruction. Thus, A. Hrytsenko emphasizes that "the depth of modernization, which is determined by the transition from external forms to load-bearing structures of internal content, is the limit of the transformation of modernization into reconstruction" ${ }^{2}$. That is, the reconstructive development of the economic system is a development that can be achieved by restructuring the basic structures of the economic (economic) system, changing its structure. Since the content of reconstructive economic development includes the social

${ }^{2}$ Hrytsenko A. (2016). Rekonstruktyvnyj ekonomichnyj rozvytok, zmist, osnovni naprjamy i vektor socialjnoji spravedlyvosti [Reconstructive economic development, content, main directions and vector of social justice]. Economic theory. Vol. 4, pp. 5-19. 
orientation of change, it is achieved both in terms of economic growth and at the stage of recession.

A. Hrytsenko emphasizes in his research the need to take into account the laws of architecture (the fundamental structure of integral systems), as one of the important features of the paradigm of reconstructive development of the modern economic system. In real economic practice, it is necessary to take into account the internal characteristics and nature of integrity, but it only modifies, adjusts the proportions, not cancels them. Since the structure of the system (whole) is deformed, away from equilibrium proportions, it is advisable to pursue a policy aimed at overcoming imbalances and approaching equilibrium proportions (with correction of deviations of not more than $15 \%$ of existing averages), which is the principle of gradual equilibrium. economic system.

Thus, the problems of modernization of the modern economy, the "architectonics" of the economic system (according to A. Hrytsenko), the issues of inclusive development are extremely relevant for determining the vector of development of the national economic system. In the broadest sense, the concept of inclusive development means the development of national economies in world economic relations, which makes it possible to include and reveal the internal potential of all elements, all actors of the socio-economic system of the country and ensure its balance. We believe that systemic inclusiveness is needed by the national economic system. This will provide opportunities to identify natural, social and cultural benefits of the system, ensure sustainable development and improve the welfare and quality of life of citizens in society by radically restructuring the economy and deploying its internal potential in reflective interaction of the economic system with the environment.

The introduction of the model of mechanisms of public management of inclusive development of the country is focused on overcoming a number of problematic issues facing Ukraine in the direction of its inclusive development.

\section{Genesis of scientific approaches to the definition of transport infrastructure and "smart city"}

At the present stage, developed and developing countries are characterized by the transformation of transport from the material base of the circulation process to an intersectoral complex, which determines not only the development of the economy, living standards, but also the ability of the state to achieve foreign economic and political goals. 
The formation of a mixed type of economy in most countries presupposes the simultaneous functioning of state and private ownership of the means of production with the provision of the public sector with regulatory functions, ensuring market competitiveness, environmental and social security, innovation and compliance with social guarantees. At the same time, the development of the transport industry in any country remains under special attention by the state for a number of reasons, including:

- transport activities need to be regulated due to the need to ensure public (environmental, traffic safety) and national security;

- certain sectors of the transport sector belong to the natural monopoly, which ensures the integrity of the economic space (for example, highways, railways, seaports, airports, etc.). The activities of such natural monopolies are regulated by the state. In the absence of real competition for consumers and responsibility to owners, the effectiveness of such management is often low.

Therefore, we must summarize that the process of formation of transport infrastructure is very complex, continuous and involves the active participation of all without exception, the subjects of relations in the national economy. This is especially evident with the personal participation of public authorities through the use of economic and legal regulation. The transition from a centrally regulated economy to a market economy has led to a change in the reproductive structure of the economy and, accordingly, a qualitative change in transport infrastructure in terms of properties, types, and shape.

Applying the methodology of studying the genesis of economic systems to study the development of transport infrastructure, we can distinguish the following stages: the formation of transport infrastructure necessary and sufficient prerequisites, conditions, resources and factors for a special sphere of transport services based on social division of labor; emergence and approval of developed forms of species, level, territorial and other types of transport infrastructure (primarily transformational) as the relationship between different actors of the national economy; mainly intensive advanced development of transport infrastructure (especially its transactional part) as a dominant component of the modern and future socially oriented market economy. 
Analysis of the results of research conducted by scientists ${ }^{3}$, led to the conclusion that the economic content of the transport infrastructure of the country is revealed through a number of its functions, in particular:

- providing, which consists in creating general conditions for the implementation of all stages of the reproduction process: production, distribution, exchange, consumption. uninterrupted supply of resources to producers, goods to consumers. The rhythm of supply and the dynamics of growth of material production and trade are directly affected by the availability of appropriate transport services, which in turn depend on the availability and capacity of the transport network;

- regulatory, under which the transport infrastructure is a tool for implementing the state policy of socio-economic development of individual regions and cities. Transport infrastructure projects are capital and labor intensive. In times of economic crisis, governments often implement such projects in order to accelerate the exit from the crisis, reduce its negative pressure on society by creating new jobs. As a result, the newly created transport infrastructure facilities (highways, airports, river and sea ports, railways) become "catalysts" for the recovery of the country's economy;

- stimulating, which consists in creating preconditions for intensification of investment activity in the region, increase of efficiency of functioning of other branches of material production and social sphere. Thus, the construction of new communication networks leads to an increase in capital investment in industrial and residential construction in previously sparsely populated areas, promotes labor migration, increases the volume of industrial and agricultural production;

- social, which is to create the conditions for the efficient operation of passenger transport. In particular, the level of accessibility of transport services directly affects the savings or time losses of the population associated with their relocation and creates the conditions for labor migration both within the region and the country;

- productive, which consists in the direct participation of the subjects of transport infrastructure in the creation of material objects.

Thus, performing these functions, transport infrastructure makes a significant contribution to accelerating the development of the national

\footnotetext{
3 European Smart Cities (version 4.0 (2015)). - Retrieved from: http://www.smart\%cities.eu./?cid=2\&ver=4.
} 
economy by increasing the efficiency of transport processes and providing a range of transport services, creating favorable conditions for business development - in line with national economic interests.

Given the importance of the role of forming a high-quality comprehensive system to meet the interests and needs of municipal residents, the problems of defining the concept of "smart city" and "smart city management" are given attention to a wide range of scientists, including foreign ones. Historically, the study of the concept of "smart city" in the categorical apparatus of public administration science is revealed in several parallel planes: the evolution of society from industrial to post-industrial and from information to smart society and the construction of appropriate multilevel and multidirectional management systems.

Accordingly, today the term "Smart" means a certain property of the control object, which characterizes the integration of elements, previously incompatible, which are currently carried out using Internet communications (Smart-Phone, Smart-TV, Smart-Home). In recent years, new global trends in the development of smart-objects of management have become actively used: "smart-solutions", "smart-systems", "smartcities", "smart-countries". But for the first time the term smart city in the context of a smart society living in its territory was introduced by $\mathrm{P}$. Drucker ${ }^{4}$. Then, in 1954, this term became a symbolic designation, an abbreviation of a complex "balancing development" concept.

Also, according to the approach proposed by P. Drucker, there are a number of criteria that must meet the management goals that must be written in the context of "smart management" of such development:

1) specific - specific (what needs to be achieved?);

2) measurable - in what will the result be measured?

3) attainable - achieved (due to which it is possible to achieve the goal);

4) relevant - relevant (determining the truth of the goal);

5) time-bounded - correlation with a specific period (determination of the time period after which the goal must be achieved) [3].

Thus, the term "Smart" is a complex concept that contains at least five diverse characteristics. In the translation of this word from English

\footnotetext{
${ }^{4}$ European Commission Investing in the Low Carbon Technologies // SET-Plan. 2009. - Retrieved from: http://ec.europa.eu/eip/smartcities/index_en.htm
} 
to Ukrainian we get a generalized "smart", ie one that promotes the mutually agreed development of smart technologies.

According to the content of this term, according to I.A. Ternova, the key property of "smart" is the ability to interact with the environment, so smart - is a property of the system or process, which is manifested in interaction with the environment and gives the system the ability to: 1) adaptations to languages that are constantly and incessantly transformed; 2) independent development and self-control; 3) effective achievement of the result, which, in our opinion, in the context of the study of the term "smart" at the level of city management, is to ensure its sustainable development.

Within the study of various aspects of sustainable urban development, there are two main approaches to the consideration of the term modern city. These are "smart city" and "electronic city". And if 5 years ago these concepts could be clearly distinguished, now there is a complete transformation of approaches to understanding the essence of these concepts. Thus, according to S.A. Chukut and V.I. Dmitrenko, smart city (smart city) is a concept that is directly related to the automation of city life and its certain robotics.

According to A. Greenfield, over the past decade, due to mass access to the Internet and the miniaturization of electronics, the development of nanotechnology, the concept of "smart city" is mainly established in the sense of the city as an efficient robot ${ }^{5}$. This idea originated with technology corporations IBM, Cisco, Microsoft and Software AG, which expected to make a significant profit from municipal contracts. As. A. Greenfield notes in his book Against a Smart City, "the concept of a smart city in its full modern form comes from these companies rather than from any party, group or person known for their contribution to the theory or practice of urban planning" [ 19], ie not relevant to public administration.

A similar opinion is held by M.V. Boykova, who proposed to classify large cities that are heading to "smart" their services, into three types:

- cities-magnets - large economic centers or capitals that attract residents with employment opportunities and comfortable living,

\footnotetext{
${ }^{5}$ Greenfield A. Against the Smart City / A. Greenfield. - 2013. - Retrieved from: http://www.academia.edu/6732875/Emerging_Markets_and_\%Digital_Economy_Building _Trust_in_the_Virtual_World_032_
} 
- strategic cities that implement high-tech projects, develop innovative concepts, the priority of which is to increase the comfort of life of their residents in the long run,

- cities-innovators, which survived the crisis due to the decline of traditional sectors of the economy, and were able to apply an innovative approach to creating new growth points and attracting intellectual resources.

That is, according to the proposed concept, smart cities are not considered as objects of public administration, but as objects of spontaneous socio-economic movement, which can not always be directed in a given strategic direction.

Another approach is used by the developers of the European Smart Cities concept at the Vienna University of Technology. According to them, a "smart" city is a management category, a city that effectively uses all available information to better understand and control its functions and make optimal use of available resources, including residents.

What is the concept of a smart city in terms of different approaches to its modern understanding? According to MA Schneps-Schneppe, it is a "city of knowledge", "digital city", "cyber city" or "eco-city", aimed at the future. It is a city that constantly monitors the most important infrastructure in order to optimally allocate resources and ensure security. The domestic concept of "Kyiv Smart City" defines a smart city as a modern model of urban transformation, where information and technology can qualitatively improve the management system and solve the problems of the urban community. That is, the definition of a "smart city" can be approached through a system of factors that make it up. It is possible to present the conceptual meaning of the concept of a smart city in the context of its four constituent factors: institutional, technological, human and economic.

Accordingly, the institutional factors of formation and development of a smart city include a system of specialized institutions of urban space, covering the service of all spheres of life of the urban community (education, science, employment, protection, consulting, legal aid, services and professional assistance, etc.). Technological factors are responsible for the development of machinery and technologies designed to simplify, automate and improve the work of utilities and services while minimizing the role of man in the provision of services. 
The social factor, in our opinion, is the most important component of becoming a smart city and supporting the process of its progressive development, because people, their intellectual, creative potential, ideas, experience and professional skills are the basis of systemic change. The quality and speed of these transformations also largely depends on the economic factor that enables the realization of creative potential, ideas of the urban community and its management core, so the economic factor significantly affects all others - institutional, technological and human.

According to the outlined approach, distinguish the definition of "smart city" through the prism of institutional, social, economic, technical approaches and formed in terms of their integration management approach.

Thus, in our opinion, a "smart city" in the context of ensuring the development of a large city is: a "smart community", formed and united around a system of specialized institutions integrated into the urban space, from the standpoint of an institutional approach; living space of increased comfort, created, in particular, through the effective use of the human factor, intellectual capital as a basis for progressive institutional and economic transformations in the city, from the standpoint of social approach; economically viable urban system of generation and efficient distribution of public goods, capable of accelerated development and improvement through a combination of full-fledged financial security with technological saturation and social readiness for self-development, from the standpoint of economic approach.

Grouping the definitions of previous researchers according to one of the four approaches we have identified allows us to summarize the results and formulate our own definition of "smart city" as a complex and multifactorial municipal system containing institutional, social, economic, environmental, technological component, effective coherent and integrated whose work ensures the sustainable development of the city, increasing the comfort of using improved services.

However, it should be noted that the concept of "smart city" is constantly being modernized, gaining new features in an era of rapid development of technology, which gives it more and more new and indepth characteristics. Therefore, the prospect of further research in this direction is an in-depth study of this constantly updated system of factors for the formation of such cities and determine on their basis the conceptual content of the municipal smart system. 
Based on the results of analyzing the content of the concept of "smart city" through the prism of institutional, social, economic, technical and integrated management approaches proposed by previous researchers, the author improved the conceptual and categorical apparatus of the subject area - approaches to ensure the development of large cities. "Smart city", interpreted as "city of knowledge", "digital city", in which all its subsystems are coordinated.

In a general sense, this is a system that allows the most efficient use of existing resources of urban services and ensure maximum security of urban life. Such a city is constantly increasing the number and quality of services provided to the population, providing a sustainable environment that promotes comfort and quality of life.

From the standpoint of public administration, a smart city is a managed integrated and multifactorial municipal system that incorporates these components and fits them into the context of sustainable development. The purpose of the development of this system is to ensure increased comfort of urban life and safety of the environment - a key requirement that will always determine the content of the criterion of "reasonableness" in city management.

The set of scientific provisions that will create a methodological basis for the implementation of the processes of formation and continuous improvement of the "smart city" system for large cities in Ukraine through the introduction of appropriate methodological and technological support of these processes needs further substantiation.

Formation of methodical and applied bases of strategic planning of transport infrastructure development in the system of economic security of the state assumes expediency of development of strategies and strategic directions of this development taking into account use of opportunities and prevention of occurrence and realization of traditional and hybrid threats to economic security of the state.

\section{CONCLUSIONS}

Thus, in order to make the most of the benefits of e-government at both the national and local levels, the risks of its implementation should be minimized. To this end, there should be an active dialogue between the government and citizens for the further development of e-democracy, coordination of efforts of public authorities and local governments to 
develop mechanisms to address these problems and prevent their occurrence in the future.

From all the above we can conclude that a smart city is a city of knowledge, a digital city, a cyber city or an eco-city in which communal systems are organically coordinated. This is a system that allows the most efficient use of available resources of city services and ensure maximum security of city life. Such a city is constantly increasing the number and quality of services provided to the population, providing a sustainable environment that promotes the well-being and health of citizens, improving comfort and quality of life. The historical preconditions for the formation of a smart city provided for the combination of different management systems into a holistic organic unity in order to achieve a synergistic effect of city management by streamlining different areas of utilities, medicine, education, culture and more. For the successful implementation of SMART-approaches to the development of large cities, the priority tasks are the development of appropriate regulatory and methodological and technological support (both at the national, regional and local levels); formation of general and local systems of social, economic, ecological, food security; development of civic initiatives and social responsibility in this area; implementation of programs and projects for the formation of the economic basis of structural transformations of institutional, socioecological and economic systems of large cities.

The complex of innovative tools of community development of a big city needs further scientific elaboration, the key characteristics of which should be the mutual integration of its subsystems, the coherence of services and the focus on the comfort of citizens.

\section{SUMMARY}

The conceptual bases of the system of public management of the development of the transport infrastructure of the modern city are substantiated in the work; the genesis of scientific approaches to the definition of transport infrastructure and "smart city" is analyzed; the ways of management of development of a transport infrastructure of the city on the basis of public management are offered. 


\section{REFERENCES}

1. Komninos, N., Kakderi, C., Panori, A., \& Tsarchopoulos, P. (2018). Smart City planning from an evolutionary perspective. Journal of Urban Technology. Retrieved from https://doi.org/10.1080/ 10630732.2018.1485368

2. Yigitcanlar, T., Kamruzzaman, M., Buys, L., Ioppolo, G., Sabatini-Marques, J., Moreira Da Costa, E., \& Yun, J. J. (2018). Understanding 'smart cities': Intertwining development drivers with desired outcomes in a multidimensional framework. Cities. Retrieved from https://doi.org/10.1016/j.cities.2018.04.003

3. Kyiv Smart City Concept: Website (2018). Retrieved from https://www.kyivsmartcity.com/?lang=en

4. The Smart City Model: Website (2018). Retrieved from http://www.smart-cities.eu/?cid=2\&ver=4

\section{Information about the author: Zemliak A. O.,}

Postgraduate Student at the Department of Social and Humanitarian Kharkiv Regional Institute of Public Administration of the National Academy of Public Administration under the President of Ukraine 75, Moskovsky avenue, Kharkiv, 61000, Ukraine 